\title{
Combined use of high-reflective index vitrectomy meniscus contact lens and a noncontact wide-angle viewing system in vitreous surgery
}

This article was published in the following Dove Press journal:

Clinical Ophthalmology

9 August 201 I

Number of times this article has been viewed

\section{Hisato Ohno}

Inouye Eye Hospital, Chiyoda-ku, Tokyo, Japan
Correspondence: Hisato Ohno Inouye Eye Hospital,

4-3 Kanda-Surugadai, Chiyoda-ku, Tokyo, I0I-0062, Japan

Tel +81332950911

Fax +8I3 32930917

Email oono-h@inouye-eye.or.jp
Background: The aim of this study was to assess the combined use of a high-reflective index vitrectomy (HHV) meniscus contact lens and a noncontact wide-angle viewing system in vitreous surgery.

Methods: Twenty-three gauge vitrectomy was performed with combined use of a HHV meniscus contact lens and a noncontact wide-angle viewing system. When delicate manipulation of the retina such as internal limiting membrane peeling was performed, only the HHV meniscus lens was used.

Results: Advantages of this combination procedure include the ability to observe the peripheral fundus image, easy access to the posterior pole without exchange of the contact lens when needed, keeping the corneal surface wet covered by a contact lens, and the good view afforded during fluid-air exchange.

Conclusion: Combined use of a HHV meniscus contact lens and a noncontact wide-angle viewing system is useful for vitreous surgery. It has the advantages of both contact and noncontact wide-angle viewing systems.

Keywords: fundus, fluid-air, surgery

\section{Introduction}

The wide-angle viewing system allows a panoramic view through a small pupil, intraocular lens intraoperatively, even under fluid-air conditions. The wide-angle viewing system is divided into two types. One is the contact type which uses a contact lens. ${ }^{1,2}$ The other is the noncontact type. ${ }^{3}$ In the contact type, the contact lens is fixed by a ring on the cornea. This type of contact lens is bigger and less stable on the cornea than the conventional contact lens for vitreous surgery. In addition, visibility abruptly worsens when the eye ball is tilted during surgery. The noncontact type is superior to the contact type for these problems. However, the corneal surface must be kept wet to maintain the visibility of the fundus. Ultimately, the aim of the wide-angle viewing system is to ensure good images of the peripheral fundus during surgery. We present here the combined use of the conventional high-reflective index vitrectomy (HHV) meniscus contact lens and noncontact wide-angle viewing system to solve these problems in two patients, both of whom provided informed consent to be treated.

\section{Methods}

Twenty-three gauge vitrectomy was performed by the combined use of a noncontact wide-angle viewing system (Eibos SPXL [132 D], Möller-Wedel, Wedel, Germany) and the HOYA HHV meniscus contact lens (Hoya, Tokyo, Japan) fixed by a ring (Figure 1). 


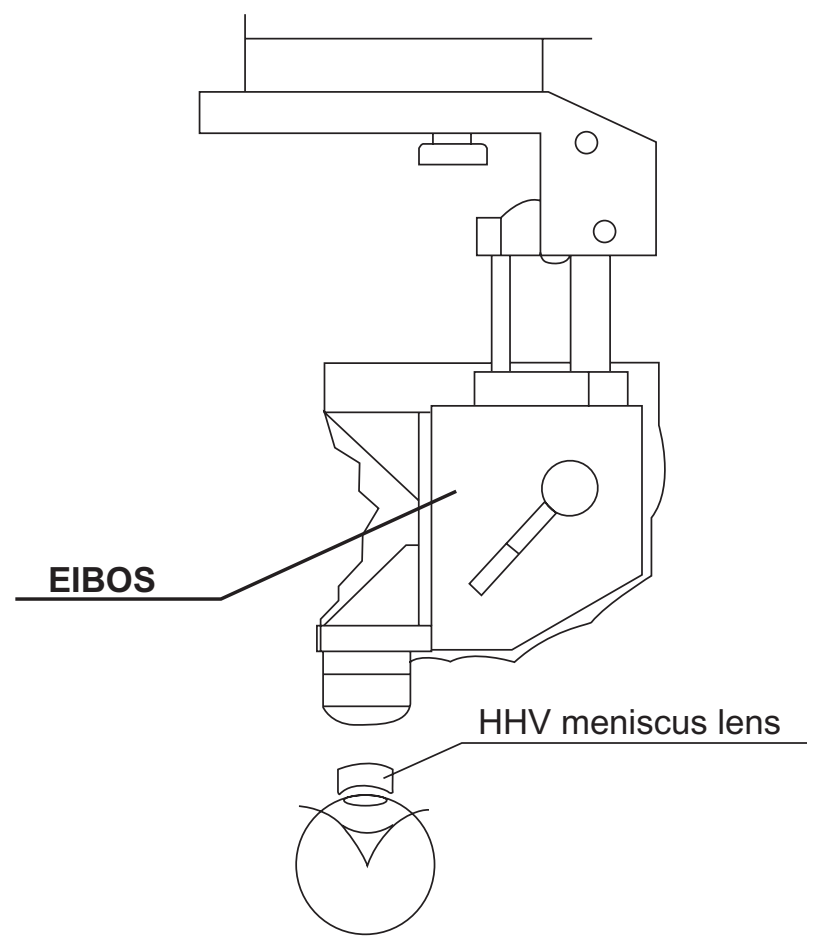

Figure I Schematic view of the setting of noncontact wide-angle viewing system and high-reflective index vitrectomy meniscus lens. The high-reflective index vitrectomy meniscus lens is fixed by the ring on the corneal surface.

The HHV meniscus lens is usually used to magnify the posterior pole for delicate manipulation, and its observable area is narrow. However, the wider area of the fundus is able to be seen by the combined use of the noncontact wideangle viewing system. In addition, clear visibility of the fundus is obtained even in the air-filled conditions of the vitreous cavity. The first case was a 66-year-old woman who presented with visual loss from vitreous hemorrhage and branch retinal vein occlusion. Twenty-three gauge vitrectomy and intraocular lens implantation was performed after phacoemulsification. The second case was a 42-year-old man seen with high myopia who had previously undergone scleral buckling for a rhegmatogenous retinal detachment. The rhegmatogenous retinal detachment recurred by new tear formation near the posterior pole at 6 o'clock. Twenty-three gauge vitrectomy was performed preserving the crystalline lens.

\section{Results}

In the first patient, the observable fundus area almost extended to the ora serrata (Figure 2). In the second patient, a good view was obtained during fluid-air exchange (Figure 3). In both cases, the corneal surface covered by a HHV meniscus lens was kept wet to maintain good visibility during surgery without assistance.

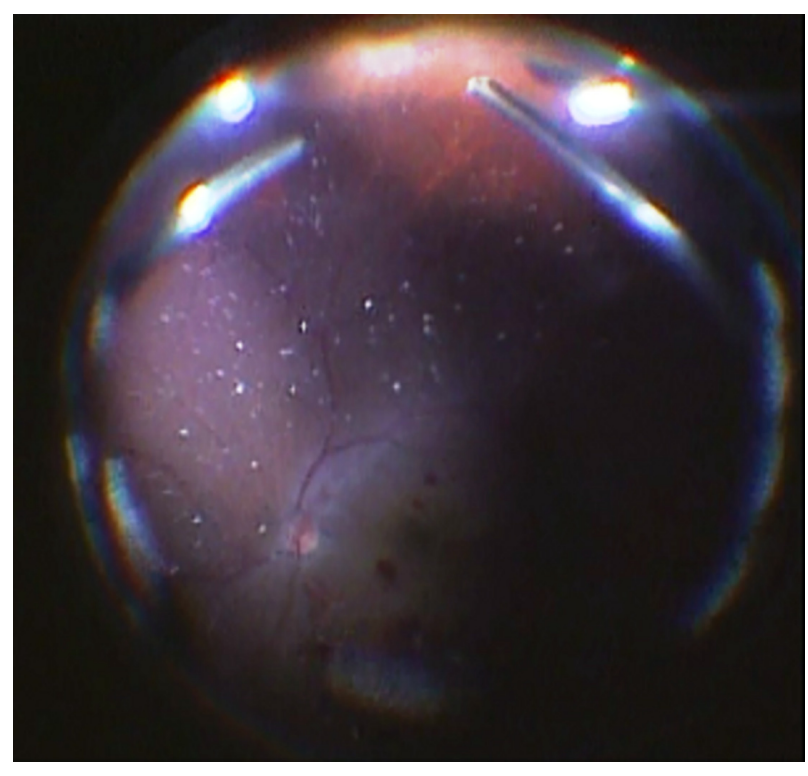

Figure 2 Intraoperative view. Combined use provides a high-quality image almost to the ora serrata.

\section{Discussion}

The noncontact wide-angle viewing system enables a wider area of the fundus to be seen than by conventional vitreous surgery, but the quality of resolution is not sufficient for delicate manipulation. In contrast, the HHV meniscus lens is usually used to magnify the posterior pole for delicate manipulation. The combination of the noncontact wide-angle viewing system and HHV meniscus lens has both advantages. The quality of the wide viewing in combination use is not inferior to the ordinary wide-angle viewing system.

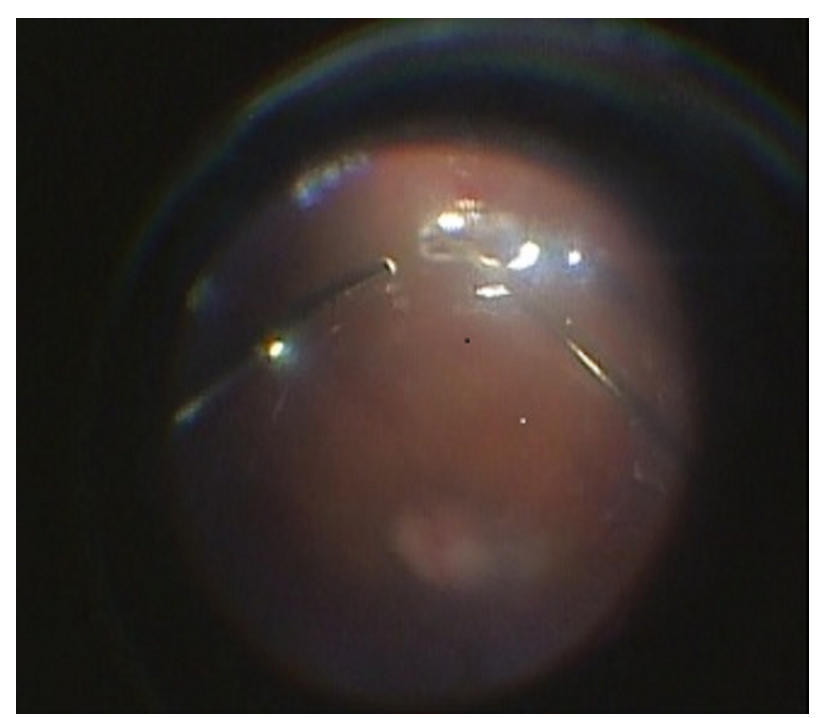

Figure 3 Intraoperative view during fluid-air exchange. A good fundus view is maintained. 
When delicate manipulation such as internal limiting membrane peeling is required, only the HHV meniscus lens is easily available. In addition, the corneal surface covered by the HHV meniscus lens ensures good visibility during surgery. The quality of the peripheral fundus images appears to be improved, because the contact lens eliminates naturally occurring aberrations and limits the number of reflecting surfaces. ${ }^{4}$ In addition, visibility with the combined system during fluid-air exchange is maintained at a level as good as that of the ordinary wide-angle viewing system.

We have performed many operations using this combined technique. The present paper describes the advantages in typical cases. This combined system is a promising alternative approach to the wide-angle viewing system. Further studies are required to evaluate the choice of contact lens to be used with this system.

\section{Disclosure}

The author reports no conflicts of interest in this work.

\section{References}

1. Spitznas M, Reiner J. A stereoscopic diagonal inverter (SDI) for wideangle vitreous surgery. Graefes Arch Clin Exp Ophthalmol. 1987; 225:9-12.

2. Bovey EH, Gonvers M. A new device for noncontact wide-angle viewing of the fundus during vitrectomy. Arch Ophthalmol. 1995;113: 1572-1573.

3. Nakata K, Ohji M, Ikuno Y, et al. Wide-angle viewing lens for vitrectomy. Am J Ophthalmol. 2004;137:760-762.

4. Chalam KV, Shah VA. Optics of wide-angle panoramic viewing systemassisted vitreous surgery. Surv Ophthalmol. 2004;49:437-445.
Clinical Ophthalmology

\section{Publish your work in this journal}

Clinical Ophthalmology is an international, peer-reviewed journal covering all subspecialties within ophthalmology. Key topics include: Optometry; Visual science; Pharmacology and drug therapy in eye diseases; Basic Sciences; Primary and Secondary eye care; Patien Safety and Quality of Care Improvements. This journal is indexed on

Submit your manuscript here: http://www.dovepress.com/clinical-ophthalmology-journal

\section{Dovepress}

PubMed Central and CAS, and is the official journal of The Society of Clinical Ophthalmology (SCO). The manuscript management system is completely online and includes a very quick and fair peer-review system, which is all easy to use. Visit http://www.dovepress.com/ testimonials.php to read real quotes from published authors. 